Brit. J. industr. Med., 1962, 19, 195.

\title{
INJURIES TO THE SEMILUNAR CARTILAGES OF THE KNEE IN MINERS
}

\author{
BY \\ W. J. W. SHARRARD and F. D. K. LIDDELL \\ From the Sheffield Royal Infirmary and Medical Statistics Branch, National Coal Board
}

(RECEIVED FOR PUBLICATION JANUARY 24, 1962)

Comprehensive records of 957 meniscectomies, over a period of 30 months, were obtained from five hospitals in one of the largest British coalfields. Corresponding records of 1,075 appendicectomies were collected and used as reference. The combined data provided conclusive evidence that the rate of meniscectomy was very much higher among miners than among other men. The proportions of bucket handle cartilage tears, which are a severe handicap to any individual, whether miner or not, and of other tears were very similar for miners and for others, in the various hospitals. This suggests that miners are more likely than others to suffer cartilage damage of any type.

Information was also obtained by interviewing some 200 of the miners on whom meniscectomy had been performed. This included the normal attitude at work, the attitude and activity at the time of the incident leading to the tear of the cartilage, and the mechanism of the first incident. It was clear that cartilage tears were more common in miners who knelt at work although, as often as not, the tear actually occurred when the man was walking.

From an examination of 80 consecutive patients, laxity of the knee joint was shown to result from kneeling at work. This appeared to be the initiating factor in the majority of cartilage tears, because it renders the knee more unstable and the menisci more liable to injury when rotational strains are put on the joint. External rotation of the leg on the knee, combined with abduction, when in an upright posture, appeared to be the major factor in producing tears of the medial cartilage; tears of the lateral cartilage, which were much less frequent, appeared to be caused mainly by internal rotation combined with adduction.

Measures of "good housekeeping" in maintaining better walking surfaces are very likely to reduce the number of knee cartilage injuries, by reducing the risk of stumbling and slipping. They should also reduce the incidence of other knee injuries and ligamentous strain, which between them cause a substantial proportion of mining injuries.

Experience gained by one of us (W.J.W.S.), while investigating beat knee and in the course of orthopaedic hospital practice in Sheffield and, before that, in the South of England, suggested that miners, and particularly coal-face workers, are more liable to suffer injuries to the semilunar cartilages of the knee (menisci) than other individuals. About $40 \%$ of all coal-miners work at the coal-face, where the headroom available for work depends on the thickness of the seam. In very thin seams, faceworkers have to lie down; in the thickest seams they are able to stand or at least stoop, but, in roughly half the collieries in Great Britain, seam heights of approximately 30 to $50 \mathrm{in}$. force the faceworkers to kneel at work. About 100,000 miners work on their knees, and there is a substantial number of kneeling miners in virtually all coalfields. Industrial histories of miners coming forward for meniscectomy suggested that the liability to meniscus injury might be related to the need to kneel.

An investigation was, therefore, instituted to attempt to answer the following questions:

1. Are meniscus lesions, or meniscus lesions requiring operation, more common in miners than in other workers?

2. Are meniscus lesions, or meniscus lesions requiring operation, more common in kneeling than in nonkneeling miners?

3. Is there any difference in the type of meniscus lesion in miners compared with other workers? 


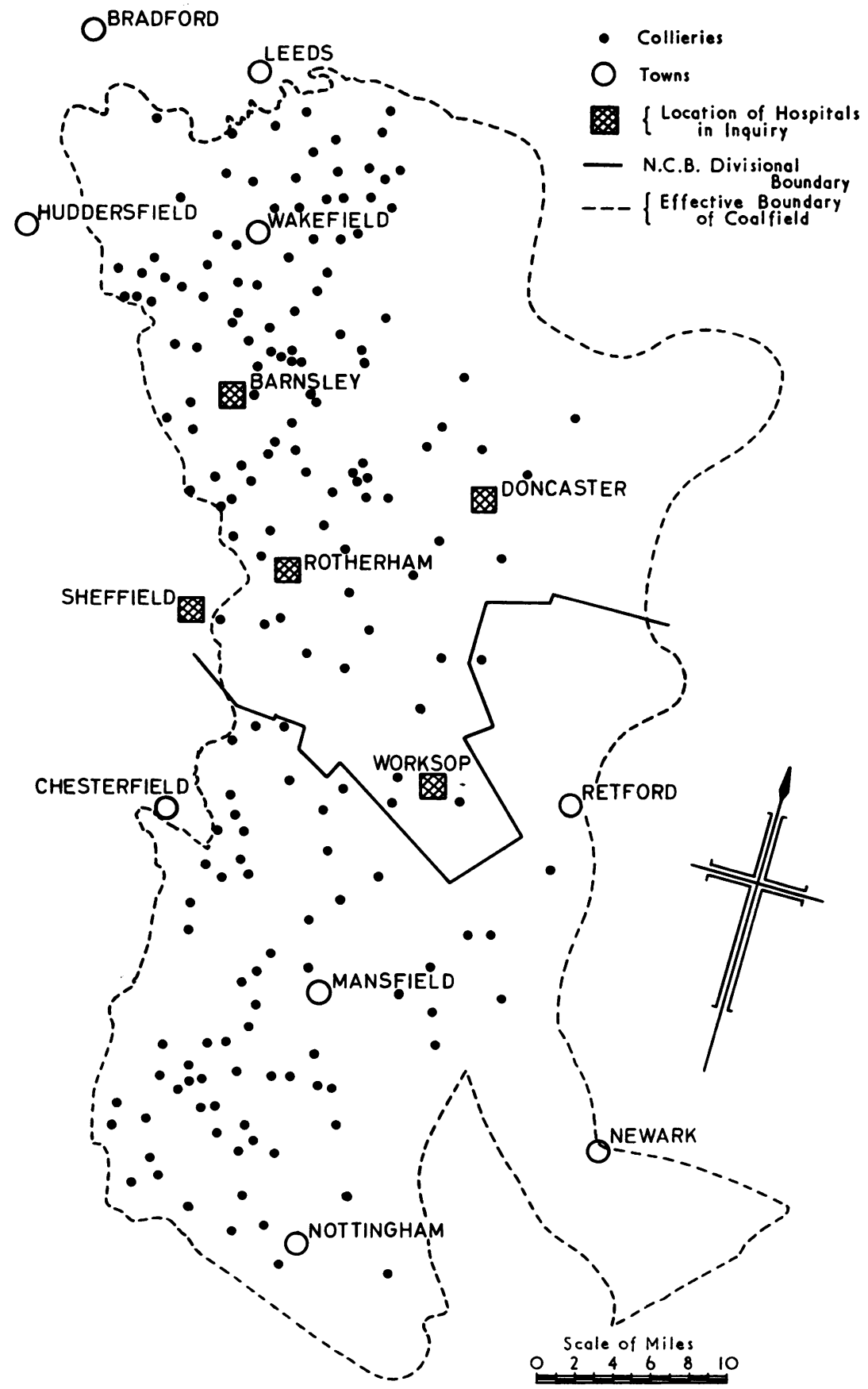

Fig.-Map of the area included in the study. 
4. Is there any difference in the type of meniscus lesion in kneeling compared with non-kneeling miners?

5. In what way does the initial trauma leading to a meniscus lesion arise in miners?

6. Does the normal attitude at work of a miner affect his liability to a meniscus lesion?

7. What are the common mechanisms that produce a meniscus lesion?

8. If kneeling predisposes to meniscus lesions, how may it do so?

9. Can any measures be taken to minimize the liability to meniscus lesions in miners?

\section{Method of Study}

It was decided that the material for the investigation should be obtained from hospital records of men between the ages of 15 and 64 who had had an operation to remove one or other meniscus. In this way, it would be more certain that a patient actually had a torn meniscus. It was appreciated that the material would thus include only those in whom the meniscus lesion had warranted operation and that there could have been individuals, miners or nonminers, who might have suffered meniscus lesions but who either did not have symptoms sufficient to present themselves for medical advice or had not been considered suitable candidates for operative exploration. It is thus possible that miners, by the nature of their work, would be more liable to present themselves for medical advice or operation than non-miners; nevertheless, any individual, whether a miner or not, who suffers a bucket handle tear of a meniscus is very severely handicapped, and it was felt that patients with lesions of this kind might present a comparable standard in the two categories of population.

Records were investigated at the following hospitals: Beckett Hospital, Barnsley; Royal Infirmary, Doncaster; Doncaster Gate Hospital, Rotherham; Royal Infirmary, Sheffield; Victoria Hospital, Worksop. These hospitals serve community needs in a fairly representative area of Yorkshire and its surrounding coalfields, as indicated in the map. Some would be more liable to admit miners because of the greater proportion of miners resident in the area; others would normally take a more varied populace. In what follows, the hospitals are identified by letters which do not correspond in order to the list above.

Hospital records of all kinds were consulted for meniscectomies performed in the $\mathbf{3 0}$ months from January 1958 to June 1960. From these records were extracted the name and age of each male patient aged between 15 and 64 ; his occupation; the meniscus affected-whether left or right knee and whether lateral or medial; and the type of meniscus lesion found at operation.

From among the miners in this series, a number were interviewed to obtain details of their normal attitude at work, their attitude and activity at the time of the first incident leading to a meniscus lesion, the mechanism of the first incident, and such other information as might be relevant to the investigation. From these more detailed studies it was hoped that information could be obtained that might give help in answering some of the questions listed above.

From the same hospitals the age and occupation of male patients in the same age range admitted for appendicectomy during the same period were also obtained to allow occupational comparisons.

\section{The Data}

Details of the numbers of meniscectomies are given in Table 1; where the occupation was in doubt the case was included as a non-miner. It will be seen that the proportion of miners interviewed varies markedly from hospital to hospital, being less than a quarter at Hospital $\mathrm{A}$, but over half at Hospital B. This variation arose because of the methods adopted for obtaining interviews, which differed according to local needs. However, as no major differences were found in the information collected at interview from the patients of the various hospitals, no serious inaccuracies in interpretation appear likely to be introduced for this reason.

The types of meniscus lesion discovered were categorized as: bucket handle tear; posterior horn tear; central tear; anterior horn tear; multiple lesions; other abnormalities (cystic, discoid, calcified, degenerative); normal cartilage and those with inadequate information as to the type of cartilage lesion.

The information obtained at interview was classified as follows:-

Normal working attitude, distinguishing: sitting or squatting; kneeling with leg or legs externally rotated; kneeling with leg or legs internally rotated; kneeling on heels; kneeling upright or crawling; walking, standing or stooping; other.

Attitude at time of lesion, distinguishing in the same way.

Activity at time of lesion, distinguishing: normal work; walking to or from work at the colliery; other work at the colliery; sport; other.

Knee movement at the time of lesion, resolved into three possible mechanisms: external rotation combined with abduction of the leg on the knee; internal rotation combined with adduction of the leg on the knee; movements of the knee not involving 
TABLE 1

NUMBERS OF MENISCECTOMIES AND APPENDICECTOMIES

\begin{tabular}{|c|c|c|c|c|c|c|}
\hline & \multicolumn{6}{|c|}{ Hospital } \\
\hline & $\mathbf{A}$ & B & $\mathbf{C}$ & $\mathbf{D}$ & $\mathbf{E}$ & All \\
\hline $\begin{array}{l}\text { Meniscectomies* } \\
\text { Mining occupations } \\
\text { Interviewed } \\
\text { Not interviewed }\end{array}$ & $\begin{array}{r}55 \\
193\end{array}$ & $\begin{array}{l}50 \\
40\end{array}$ & $\begin{array}{l}32 \\
71\end{array}$ & $\begin{array}{l}27 \\
51\end{array}$ & $\begin{array}{l}43 \\
43\end{array}$ & $\begin{array}{l}207 \\
398\end{array}$ \\
\hline $\begin{array}{l}\text { Total } \\
\text { Other occupations } \dagger\end{array}$ & $\begin{array}{r}248 \\
62\end{array}$ & $\begin{array}{r}90 \\
161\end{array}$ & $\begin{array}{r}103 \\
50\end{array}$ & $\begin{array}{l}78 \\
50\end{array}$ & $\begin{array}{l}86 \\
29\end{array}$ & $\begin{array}{l}605 \\
352\end{array}$ \\
\hline Total & 310 & 251 & 153 & 128 & 115 & 957 \\
\hline $\begin{array}{l}\text { Appendicectomies } \\
\text { Mining occupations } \dagger \\
\text { Other occupations }\end{array}$ & $\begin{array}{l}83 \\
98\end{array}$ & $\begin{array}{r}37 \\
210\end{array}$ & $\begin{array}{l}172 \\
280\end{array}$ & $\begin{array}{l}14 \\
33\end{array}$ & $\begin{array}{l}59 \\
89\end{array}$ & $\begin{array}{l}365 \\
710\end{array}$ \\
\hline Total & 181 & $247 \ddagger$ & 452 & 47 & 148 & 1,075 \\
\hline
\end{tabular}

*26 men had two separate operations on different cartilages and both are included in these figures.

tIncluding cases where the occupation was in doubt.

†Sampled, out of a total of 391 appendicectomies performed, by including only the cases operated on by certain of the surgeons concerned. As each of the surgeons took days in turn for admissions, the sample is considered to be representative.

TABLE 2

TYPE OF LESION FOUND

\begin{tabular}{l|r|r|r|r|r|r}
\hline & \multicolumn{3}{|c|}{ Hospital } \\
\cline { 2 - 7 } & A & B & C & D & E & All \\
\hline Lesion: & & & & & & \\
$\quad$ Bucket handle tear & 57 & 86 & 51 & 49 & 30 & 273 \\
$\begin{array}{l}\text { Posterior horn tear } \\
\text { Central tear }\end{array}$ & 119 & 52 & 43 & 24 & 17 & 255 \\
$\begin{array}{l}\text { Anterior horn tear } \\
\text { Multiple lesion }\end{array}$ & 16 & 18 & 19 & 17 & 5 & 75 \\
\hline$\quad$ Total & 22 & 8 & 4 & 3 & 12 & 62 \\
\hline Other abnormality & 224 & 188 & 126 & 100 & 68 & 706 \\
\hline $\begin{array}{l}\text { Inadequate information } \\
\text { No cartilage lesion }\end{array}$ & 28 & 25 & 10 & 10 & 4 & 77 \\
\hline$\quad$ found & 39 & 33 & 13 & 10 & 26 & 73 \\
\hline \multicolumn{1}{|c|}{ All } & 310 & 251 & 153 & 128 & 115 & 957 \\
\hline
\end{tabular}

TABLE 3

RELATIVE FREOUENCY OF MENISCECTOMY IN MINERS AND OTHERS

\begin{tabular}{|c|c|c|c|c|c|}
\hline \multirow{2}{*}{$\begin{array}{c}\text { Age } \\
\text { Group }\end{array}$} & \multicolumn{5}{|c|}{ Hospital } \\
\hline & $\mathbf{A}$ & B & C & $\mathbf{D}$ & $\mathbf{E}$ \\
\hline $\begin{array}{l}15-24 \\
25-34 \\
35-44 \\
45-54 \\
55-64\end{array}$ & $\begin{array}{r}2.6 \\
13.5 \\
6.5 \\
2.4 \\
1.6\end{array}$ & $\begin{array}{l}1.9 \\
5.5 \\
4.0 \\
4.7 \\
2.2\end{array}$ & $\begin{array}{l}5.0 \\
4.0 \\
3.5 \\
4.3 \\
1.6\end{array}$ & $\begin{array}{l}1 \cdot 5 \\
8 \cdot 3 \\
4 \cdot 1 \\
5 \cdot 3 \\
\infty\end{array}$ & $\begin{array}{r}2 \cdot 0 \\
3 \cdot 0 \\
22 \cdot 7 \\
1 \cdot 2 \\
-*\end{array}$ \\
\hline
\end{tabular}

*No meniscectomies were carried out at this hospital either on miners or on others in this age group.

N.B.-Many of the figures in this Table are based on very small numbers of operations and are not reliable when considered individually. either of these mechanisms, e.g. forward flexion or extension movement.

The numbers of appendicectomies are given in Table 1; where the occupation was in doubt the case was included as a miner.

\section{Rates of Meniscectomy Among Miners and Others}

In Table 2 information about the type of lesion is given for each of the five hospitals. There are marked differences in the proportions of the various types of lesion between the hospitals. However, only very slight differences could be found in the proportions within individual hospitals, for miners and for men in other occupations. Thus comparisons between miners and others can best be made in terms of definite tears, i.e. bucket handle tear, posterior or antericr horn tear, central tear, or multiple lesions.

No reliable information is available about the populations of miners and others served by the various hospitals, and so rates of meniscectomy cannot be determined directly. However, estimates of relative frequency can be obtained in terms of the numbers of appendicectomies performed, on the assumption that appendicectomy is for a condition which is non-occupational both in origin and in indication for operation; in other words, we assume that, in a particular age group in any given hospital, the appendicectomy rate will be the same for miners as for others (= $a$, say). If, then, we call the (unknown) populations of miners and others in that age group served by that hospital $P_{m}$ and $P_{o}$, the observed numbers of appendicectomies, $A_{m}$ and $A_{o}$, for miners and others respectively have expected values $a . P_{m}$ and $a . P_{o}$. Again, if the rates of meniscectomy in miners and others are $r_{m}$ and $r_{o}$, respectively, the observed numbers of meniscectomies, $M_{m}$ and $M_{o}$, have expected values $r_{m} \cdot P_{m}$ and $r_{o} . P_{0}$. Then we estimate the relative frequency of meniscectomies in miners and others by $\left(\mathrm{M}_{m} / A_{m}\right)$ / $\left(M_{o} / A_{o}\right)$ which is an estimator of $r_{m} / r_{o}$. For example, in the 15-24 age group at Hospital $A$, the information available was:

\begin{tabular}{l|c|c}
\hline & Appendicectomies & Meniscectomies* \\
\hline Miners & 28 & 13 \\
Others & 33 & 6 \\
\hline
\end{tabular}

* For definite tears, i.e. bucket handle tear, posterior horn tear, central tear, anterior horn tear or multiple lesion.

and so the relative frequency of meniscectomy among miners compared with others is estimated as $(13 / 28) /(6 / 33)=2 \cdot 56$.

The corresponding ratios for each age group in each hospital are assembled in Table 3. None of them can, by itself, be considered reliable because 
of the small numbers of cases involved, but each one of the 24 ratios is greater than 1, indicating a higher rate of meniscectomy among miners than among others.

In view of this complete consistency there can be little doubt that meniscectomies in miners are more frequent per head of population than in men in other occupations.

In the foregoing analysis, the case has been biased against the hypothesis of a higher meniscectomy rate among miners in the allocation of men of unknown occupation, i.e. to the non-mining group for meniscectomies and to the mining group for appendicectomies. A further bias can be introduced by considering only the definite tears among miners but comparing with all meniscectomies, even including those where no lesion was found, in others. Even then, all the ratios corresponding to those of Table 3 are greater than 1 . Indeed, when the rates of bucket handle tears (which are considered to incapacitate for any occupation) among miners are compared with rates of all definite tears amongst other occupations, the general tendency is still for miners to have higher relative frequencies.

The evidence is thus clear that miners have a higher than average rate of meniscectomy. The excess is difficult to measure in view of the differences in the ratio from age to age and from hospital to hospital, but an estimate can be made from the figures of Table 3. They suggest that between the ages of 25 and 54 , miners are four to five times as likely to require meniscectomy as are other men, while among men younger than 25 and older than 54 miners are twice as likely to require meniscectomy*. These estimates are strictly applicable only to the coalfields in which the particular miners considered worked; they may vary with the risks of cartilage tears (kneeling at work and rough walking surfaces; see below) in different coalfields, although none is free from these hazards.

*These estimates are based on the medians of each row of figures in Table 3 .

\section{Statistical Examination of Aetiology of Cartilage Tears in Miners}

In an attempt to cast light on the aetiology of cartilage tears in miners, an analysis was made of the information obtained from the miners who were interviewed. In 44 of these cases either no lesion was found, or information on the lesion was inadequate, or the abnormality found was not a cartilage tear. These cases have been deleted from the further inquiry, leaving 163 for investigation. In the majority of these (126 cases) the lesion was reported to have occurred while the man was at his normal work, in a further 20 while he was walking to and from his work at the colliery, and in four more while at other work in the colliery. These 150 cases (excluding also from the 163 cases the four who suffered their injuries at sport, five in other activities, and four unknown) have been the subject of detailed examination.

Table 4 relates occupation to working attitude in these 150 cases and suggests fair internal consistency in the recording of these items. Unfortunately, the records were not always sufficiently detailed to allow accurate classification according to place of work. Some of the 36 men grouped as in "coal-face work or work elsewhere underground" and some of the men whose occupation within mining was unknown may well have been coal-face workers; indeed most of the 30 men in these two groups whose normal working attitude was not walking, standing, or stooping were probably employed on coal-face work. Thus the number of meniscectomies among coal-face workers was at least 84 out of 150 , i.e. $56 \%$, and probably rather higher, perhaps up to 114 , i.e. $76 \%$. In the North Eastern and East Midlands Divisions of the National Coai Board, from which the five hospitals of this survey drew all their cases, the proportion of coal-face workers (excluding under-officials) amongst miners generally was, in the middle of the period covered by the survey, about $38 \%$. Thus there is a considerably higher rate of meniscectomy among coal-face

TABLE 4

NORMAL WORKING ATTITUDE AND OCCUPATION IN 150 CASES COVERED BY INTERVIEW WHO SUFFERED LESION AT WORK

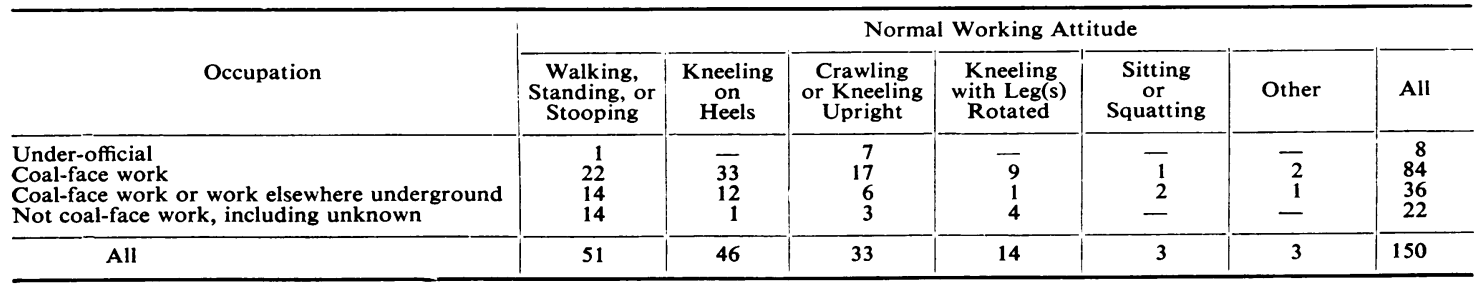


TABLE 5

ATTITUDE AT TIME OF LESION COMPARED WITH NORMAL WORKING ATTITUDE IN 150 CASES COVERED BY INTERVIEW WHO SUFFERED LESION AT WORK

\begin{tabular}{|c|c|c|c|c|c|c|c|}
\hline \multirow[b]{2}{*}{ Attitude at Time of Lesion } & \multicolumn{7}{|c|}{ Normal Working Attitude } \\
\hline & $\begin{array}{l}\text { Walking, } \\
\text { Standing, or } \\
\text { Stooping }\end{array}$ & $\begin{array}{c}\text { Kneeling } \\
\text { on } \\
\text { Heels }\end{array}$ & $\begin{array}{l}\text { Crawling } \\
\text { or Kneeling } \\
\text { Upright }\end{array}$ & $\begin{array}{c}\text { Kneeling } \\
\text { with Leg(s) } \\
\text { Rotated }\end{array}$ & $\begin{array}{c}\text { Sitting } \\
\text { or } \\
\text { Squatting }\end{array}$ & Other & All \\
\hline $\begin{array}{l}\text { Walking, standing, or stooping } \\
\text { Kneeling on heels } \\
\text { Crawling or kneeling upright } \\
\text { Kneeling with leg(s) rotated } \\
\text { Sitting or squatting } \\
\text { Other }\end{array}$ & $\begin{array}{r}47 \\
2 \\
-1 \\
1\end{array}$ & $\begin{array}{r}12 \\
26 \\
3 \\
5 \\
\end{array}$ & $\begin{array}{r}5 \\
3 \\
23 \\
1 \\
1\end{array}$ & $\begin{array}{l}\frac{6}{2} \\
\frac{5}{1}\end{array}$ & $\bar{z}$ & $\begin{array}{l}\frac{1}{二} \\
\frac{2}{2}\end{array}$ & $\begin{array}{r}71 \\
31 \\
28 \\
6 \\
9 \\
5\end{array}$ \\
\hline All & 51 & 46 & 33 & 14 & 3 & 3 & 150 \\
\hline
\end{tabular}

TABLE 6

ATTITUDE AT TIME OF LESION, KNEE MOVEMENT AND CARTILAGE TORN IN 150 CASES COVERED BY INTERVIEW WHO SUFFERED LESION AT WORK

\begin{tabular}{|c|c|c|c|c|c|c|}
\hline \multirow[b]{2}{*}{ Attitude at Time of Lesion } & \multicolumn{3}{|c|}{ Medial Cartilage } & \multicolumn{3}{|c|}{ Lateral Cartilage } \\
\hline & $\begin{array}{l}\text { External } \\
\text { Rotation/ } \\
\text { Abduction }\end{array}$ & $\begin{array}{c}\text { Internal } \\
\text { Rotation/ } \\
\text { Adduction }\end{array}$ & $\begin{array}{c}\text { Other } \\
\text { Knee } \\
\text { Movement }\end{array}$ & $\begin{array}{l}\text { External } \\
\text { Rotation/ } \\
\text { Abduction }\end{array}$ & $\begin{array}{c}\text { Internal } \\
\text { Rotation/ } \\
\text { Adduction }\end{array}$ & $\begin{array}{c}\text { Other } \\
\text { Knee } \\
\text { Movement }\end{array}$ \\
\hline $\begin{array}{l}\text { Walking, standing, or stooping } \\
\text { Kneeling on heels } \\
\text { Crawling or kneeling upright } \\
\text { Kneeling with leg(s) rotated } \\
\text { Sitting or squatting } \\
\text { Other }\end{array}$ & $\begin{array}{c}49 \\
26 \\
14 \\
2^{*} \\
6 \\
4\end{array}$ & $\begin{array}{l}\frac{4}{4} \\
4 \dagger \\
-\end{array}$ & $\begin{array}{r}9 \\
4 \\
4 \\
1 \\
1\end{array}$ & $\begin{array}{l}2 \\
\frac{1}{1} \\
-1\end{array}$ & $\frac{4}{\frac{4}{1}}$ & $\begin{array}{l}\frac{3}{2} \\
= \\
-\end{array}$ \\
\hline All & 101 & 12 & 19 & 4 & 9 & 5 \\
\hline
\end{tabular}

${ }^{*} \operatorname{Leg}(\mathrm{s})$ externally rotated. $\dagger \mathrm{Leg}(\mathrm{s})$ internally rotated.

workers than among other workers at collieries.

Table 5 compares the working attitude of these 150 cases at the time of occurrence of the lesion with their normal working attitude. A little over two-thirds (106 out of the 150) were in their normal attitude at the time of occurrence. A further 24 were walking, standing, or stooping at the time of occurrence of the lesion, although this was not their normal attitude; only 20 were in any other attitude at the time. A study of the men whose attitude at the time of the tear was not their normal attitude showed no association between the two attitudes. Although, in the classification adopted, it appears that the most common normal working attitude was walking, standing, or stooping (51 out of 150 , just one-third), very nearly two-thirds (93 out of 150) normally worked on their knees.

In Table 6 the cartilage torn is related to the attitude at the time of tear and the knee movement. It can be seen that medial cartilages were torn much more frequently than were lateral cartilages. The association between the knee movement and which cartilage is torn is of statistical significance and appears likely to be causal.

Table 7 relates the type of lesion to the attitude in the 100 cases who were interviewed and who

TABLE 7

ATTITUDE AND TYPE OF CARTILAGE LESION IN 100 CASES COVERED BY INTERVIEW WHO SUFFERED LESION AT WORK, WHO WERE AT NORMAL WORK, AND WHOSE ATTITUDE AT TIME OF LESION WAS NORMAL WORKING ATTITUDE

\begin{tabular}{|c|c|c|c|c|c|c|}
\hline \multirow[b]{2}{*}{ Attitude } & \multicolumn{6}{|c|}{ Type of Lesion } \\
\hline & $\begin{array}{c}\text { Posterior } \\
\text { Horn Tear }\end{array}$ & $\begin{array}{c}\text { Bucket } \\
\text { Handle Tear }\end{array}$ & $\begin{array}{c}\text { Central } \\
\text { Tear }\end{array}$ & $\begin{array}{c}\text { Anterior } \\
\text { Horn Tear }\end{array}$ & $\begin{array}{l}\text { Multiple } \\
\text { Lesions }\end{array}$ & All \\
\hline $\begin{array}{l}\text { Walking, standing, or stooping } \\
\text { Kneeling on heels } \\
\text { Crawling or kneeling upright } \\
\text { Kneeling with leg(s) rotated } \\
\text { Sitting or squatting } \\
\text { Other }\end{array}$ & $\begin{array}{r}17 \\
11 \\
8 \\
3 \\
1 \\
1\end{array}$ & $\begin{array}{r}14 \\
11 \\
6 \\
2 \\
1\end{array}$ & $\begin{array}{l}7 \\
1 \\
\frac{4}{1} \\
-\end{array}$ & $\begin{array}{r}2 \\
3 \\
4 \\
1 \\
-\end{array}$ & $\begin{array}{l}\frac{1}{1} \\
\frac{-}{-}\end{array}$ & $\begin{array}{r}41 \\
26 \\
23 \\
5 \\
3 \\
2\end{array}$ \\
\hline All & 41 & 34 & 13 & 10 & 2 & 100 \\
\hline
\end{tabular}


suffered their lesion at work, were at their normal work at the time of the lesion, and whose attitude at that time was their normal working attitude. There is no indication of an association between the type of tear and the attitude at work.

\section{Discussion of Statistical Results}

To some of the original questions a firm answer can be given; for others, significant trends are indicated.

There is ample evidence that meniscus lesions coming to meniscectomy are much more frequent in miners than in men of other occupations. Since the proportions of bucket handle tears and other types of tear in miners and in men of other occupations were not significantly different at any of the hospitals, it is most probably also true that meniscus tears are considerably more common in miners than in nonminers. Meniscus lesions appear to be more common in kneeling than in non-kneeling miners, but there does not appear to be any significant difference, as far as can be estimated, in the type of meniscus lesion suffered by kneeling compared with nonkneeling miners.

The study of attitudes at the time of the first incident leading to cartilage tear gave an interesting result. Of the 150 miners covered by interview who suffered a lesion at work, just two-thirds (71 who were walking, standing or stooping and 28 who were crawling or kneeling upright) were in attitudes involving movement of the knee and the remaining one-third in attitudes of a static nature. These figures compare with 51 men whose normal working attitude was walking, standing, or stooping and 33 crawling or kneeling upright, as against 66 whose normal working attitude was a relatively static kneeling one. The strong impression is gained that the incident that produces the cartilage tear is likely to be one involving movement of the knee, as in walking or crawling, more often than the lesser movements involved in kneeling; it nevertheless also seems to be true that, as two-thirds of the men normally worked on their knees, kneeling in itself predisposes to cartilage tears that may actually occur when a man is more active or undertakes sudden movements of the knee.

No satisfactory conclusion can be derived from a study of the working attitude, particularly the position of rotation of the legs, in relation to this predisposition to meniscus lesion. This arises because it is almost impossible to determine what is the exact normal attitude of work among the population of kneeling miners in general and because the attitude of kneeling was found to alter in the same miner according to circumstances from time to time.
The mechanism by which a medial or lateral cartilage is torn is, however, closely related to the mechanism of rotation. External rotation combined with abduction strain of the leg leads to tears of the medial cartilage while internal rotation combined with adduction of the leg leads to tears of the lateral cartilage, thus confirming old-established clinical impressions (Fisher, 1933).

\section{Mechanisms of Predisposition to Meniscus Lesion in Kneeling Miners}

Considerations here must be speculative. It is known that a meniscus tears because, in the course of a given strain to the knee, it becomes trapped between the femoral and tibial condyles. Longcontinued kneeling might conceivably affect the situation in one of two ways. Either the cartilage itself might be attenuated as the result of constant pressure in an abnormal position, or the stability of the knee might become altered so as to render it more susceptible to the strains that cause a cartilage tear. A study of the compression forces between the femoral and tibial condyles in the fully flexed knee in the kneeling position suggested that rather than there being an increased pressure between the condyles or the posterior parts of the condyles, it was actually less than in the standing position, much of the body weight being taken directly on to the legs below the knee.

Information about the laxity of the anterior cruciate ligament was obtained from 80 consecutive patients, 30 miners and 50 non-miners, admitted for meniscectomy during 1961, at one of the hospitals. With the knees flexed at 90 degrees, forward traction on the upper end of the tibia should normally result in no movement of the tibia on the femur. If any movement does occur, the anterior cruciate ligament in that knee must either be more lax than normal or have been ruptured. Since a tear of the medial meniscus is at times associated with a tear of the anterior cruciate ligament, a case was only recorded as positive where laxity was present in both knees, and there had been no evidence of any previous injury to the apparently unaffected knee. The evidence is presented in Table 8 which shows that some laxity of the anterior cruciate ligament may be present even in individuals who do not kneel at their work, but it appears that kneeling at work more frequently produces increased laxity of the anterior cruciate ligament, and the proposition is put forward that this renders the knee more liable to sustain a cartilage tear because of the instabilities produced when a miner is walking or crawling.

The histories given at interview suggested that there were two ways in which a cartilage tear was 
TABLE 8

LAXITY OF ANTERIOR CRUCIATE LIGAMENTS IN BOTH KNEES OF MINERS AND OTHERS

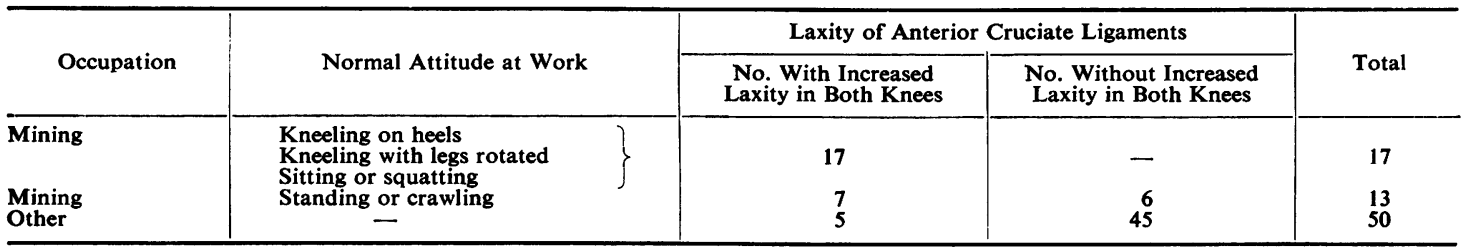

initiated. The one, in which a man, in attempting to get away from a fall of rock, would rise partially up from his knees and twist to one side to avoid it, can be reduced only by intensifying the routine safety measures of roof-control. In the other, the miner while walking sustained a rotational strain by stumbling either against an unexpected object or on uneven ground. Roadways underground in collieries often have uneven walking surfaces, usually containing tracks for haulage by tub or mine-car. There is often little room for walking past trains on these tracks and, when no train is passing, sleepers have to be negotiated. Further, equipment such as pit props, cables, girders, and bolts, may be lying in unexpected places in the roadways. Although part of the unevenness of the roadways may be caused initially by the pressures from the earth strata, much could be done to reduce it once the strata have settled down. Indeed, some simple measures of good housekeeping and attention to the surfaces walked over by miners every day might well avoid a substantial proportion of cartilage lesions. Although no analysis was made of lesions other than cartilage tears, clinical experience, including that of several National Coal Board doctors, suggests that other knee injuries and ligamentous strains occur in much the same way, and many of these too could be prevented by improved walking surfaces.
Although it has not been possible to incriminate the rotated position of the legs in kneeling as a factor causing increased liability to cartilage tears, it is an anatomical fact that extreme internal rotation of the leg causes considerable tightness of the anterior cruciate ligament and that either extreme of internal or external rotation puts the collateral ligaments on the stretch. It, therefore, seems advisable to encourage kneeling either with the heels upright or, if a rotated position of the leg must be assumed, with external rotation of the leg rather than internal rotation.

Our grateful thanks are due to the administrative staff of the various hospitals without whose helpful cooperation this survey could not have been carried out. We also wish to thank the surgeons concerned for permission to use the case notes of the patients who had been under their care, the National Coal Board for financial support, Mr. J. J. McKessack and Miss J. Templeman for their help in accumulating the data, and Dr. J. S. McLintock for much useful advice. The views expressed are, however, our own and must not be taken to commit the Sheffield Regional Hospital Board, the United Sheffield Hospitals, the National Coal Board, or any of the above-mentioned in any way.

\section{REFERENCE}

Fisher, A. G. T. (1933). Internal Derangements of the Knee-joint, 2nd ed. Lewis, London. 